\title{
Study on the Comprehension Difference between Managers and Front-Line Employees
}

\author{
W. Jiang, Z.M. Zhu, L.N. Li \\ Department of Resources and Safety Engineering \\ China University of Mining \& Technology (Beijing) \\ Beijing, China
}

\begin{abstract}
The safety signs are widely used in safety management and daily life, which is applied to instruct and manage people, safety behavior. In this paper, the author use the questionnaire survey to research the comprehension of safety signs in the workplace among managers and front-line employee in machining workshop from 6 indications namely attention, hazard perception, safety note, safety knowledge, safety awareness, safety habits. Then the author obtains some conclusions: the vast majority (over $60 \%$ ) of employees consider safety signs in the workplace are useful; over $80 \%$ of managers and front-line employees pay attention to the safety signs; over $70 \%$ of managers and front-line employees consider the safety signs really work; the front-line employees prefer to care about the effect of the safety signs can improve their hazard perception; over $65 \%$ of managers and front-line employees agree that the safety signs in the workplace have improved their safety knowledge; over $75 \%$ of managers and front-line employees think that have increase their safety awareness; over $80 \%$ of them consider the safety signs help to cultivate safety habits.
\end{abstract}

Keywords-comprehension difference; managers; front-line employees

\section{INTRODUCTION}

Safety sign can warn people potential unsafe factors more visually, and guide them to take reaction rapidly to dangerous accidents and environment in order to accidents happening[1,2].So safety signs are widely used in the safety management of the production and daily life, and to guide and control behavior of people[3].In this paper, the author studies the comprehension difference between managers and front-line employees and whether safety signs take effect or not.

\section{INTRODUCTION OF THE QUESTIONNAIRE}

\section{A. The Questionnaire}

The author researches the comprehension difference of safety signs between managers and front-line employee from six indications, namely attention, hazard perception, safety note, safety knowledge, safety awareness, safety habits, and six questions are set for the six indications. Then a questionnaire survey was conducted among employee in a coal machining welding workshop.
TABLE I. THE CONTENT OF QUESTIONS.

\begin{tabular}{|c|c|c|}
\hline No. & Indication & the content \\
\hline 1 & attention & attention people paid to the safety signs \\
\hline 2 & safety note & the effect of the safety tips \\
\hline 3 & $\begin{array}{l}\text { hazard percep- } \\
\text { tion }\end{array}$ & the effect of hazard perception \\
\hline 4 & $\begin{array}{l}\text { safety know- } \\
\text { ledge }\end{array}$ & $\begin{array}{l}\text { how much the safety signs increase person's } \\
\text { safety knowledge }\end{array}$ \\
\hline 5 & $\begin{array}{l}\text { safety aware- } \\
\text { ness }\end{array}$ & $\begin{array}{l}\text { how much the safety signs improve safety } \\
\text { awareness of human }\end{array}$ \\
\hline 6 & safety habits & $\begin{array}{l}\text { how much the safety signs improve people's } \\
\text { safety habits }\end{array}$ \\
\hline
\end{tabular}

The safety signs used in the survey safety signs in the mine workplace. Each title has three options: the option of $\mathrm{A}$ is on the positive attitude towards the relevant evaluation indication; and $B$ is the opinion that evaluation indication of safety signs takes effect but not great; $\mathrm{C}$ is on the negative attitude towards the relevant evaluation indication. Taking the evaluation indication of safety knowledge as an example, and the question is as following:

Do you think safety signs increase your safety knowledge?

A: Yes, and the effect is great.

B: Have effect but not great.

C: Do not take effect.

\section{B. The Staff Being Surveyed}

The total number of the employee in the repairing factory is 60 , and the number of employee in the machining welding workshop is only 30 , so send out 60 questionnaires. All the employee in the machining welding workshop took the questionnaires and those left questionnaires were sent out outside the machining welding workshop.

The investigators in this survey are mainly divided into two categories: the front-line employee, who work in the machining welding workshop; managers, the direct leadership of front-line employee or responsible for daily life of the workshop, such as the director, deputy director and engineers. The random sampling has been conducted to determine the sample, and 60 people has been selected: 52 front-line employee and 8 managers, as following: 
TABLE II. THE STRUCTURE PROPORTION OF THE SAMPLE.

\begin{tabular}{lll}
\hline categories & number & Percentage(\%) \\
\hline front-line employee & 52 & 86.7 \\
managers & 8 & 13.3 \\
total & 60 & 100.0 \\
\hline
\end{tabular}

\section{ANALysis OF SURVEy RESUlts}

Results of the survey are drawn in a curves, from which it is convenient to see the whole results of the front-line employee and managers, and the contradistinction of them. And then it can be seen the advantages and disadvantages of safety signs and get targeted suggestions in the further development.

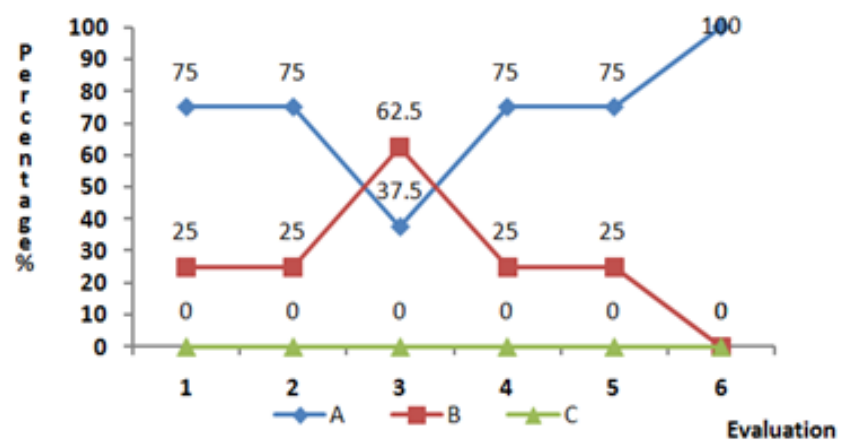

FIGURE I. THE CURVE OF THE RESULTS FROM MANAGERS.

The reason to distinguish different categories is that staffs in different levels hold different comprehension on the concept of safety culture, safety management systems[4].Managers may pay more attention to safety culture and safety management of the corporate, and what they consider is how to instill the idea of safety to employee in order to increase their safety performance and avoid accidents. However, the frontline employee may pay more attention to the job site, facilities and equipment, and salary. The difference above to safety signs is that managers force on whether safety signs reasonable and appropriate, and whether safety signs can control safety behaviors; while employee force whether safety signs relate to their facilities and equipment and process. The different focus point dues to different survey results.



FIGURE II. THE CURVE OF THE RESULTS FROM FRONT-LINE EMPLOYEES.
Through the statistics above, we can see that $\mathrm{A}$ is elected more than B and $\mathrm{C}$ almost in every question, which means safety signs in the workplace are considered useful from the overall analysis.

From the statistical linear, their is no one in management level to select $C$, which means the attitude such as "don't know”," don't understand”, “don't care” do not exist among managers and they emphasis on safety work and they think whether safety signs reasonable or not can change behaviors of the front-line employees. However ,this precisely reflects the function of safety signs for management-- improving the management's attention and support for safety signs, and strength the communication between managers and front-line employees, and this one-way, unequal communication has more influence on employees[5].However, analyzing the linear trend of option A among the front-line employees, the linear trend of option A of question 3 (hazard perception) fall down, which means people can't exactly know what danger hidden in the operating environment and what illegal behaviors should be avoided. Because some employees did not receive relevant training about safety signs and they did not research safety signs, then they cannot combine safety signs with work environment and operation process appropriately. The influence of management on the front-line employees more reflect on the recessive factors.

However, analyzing the linear trend of option A among the front-line employees, the linear trend of option A of question 3 (hazard perception) fall down, which means people can't exactly know what danger hidden in the operating environment and what illegal behaviors should be avoided. Because some employees did not receive relevant training about safety signs and they did not research safety signs, then they cannot combine safety signs with work environment and operation process appropriately. The influence of management on the front-line employees more reflect on the recessive factors[6]-the initial psychological state is improved when employees note safety signs, and then they pay more attention to safety signs, and their safety knowledge increases, and their safety awareness enhances, and form the habit of regulation operation.

\section{AnAlysis OF THE QuestionNAIRE SURVEY INDICATIONS}

From the concern extent index-personal comparison chart, we can conclude that managerial personnel and front-line staff are basically identical for the indicators of concerning on the safety sign ,the option of A( often focusing on signs)close to $80 \%$ demonstrates that safety sign system is concerned by staff, and the situation that some workers select option C (paying no attention to signs), apart from the reason of working pressure and compliance costs, are also related to enterprise's unsound safety management system, the deletion of the safety training, examination and review. To improve the situation, we should construct the enterprise safety management system at first.

It can be seen from the safety-note indication-personal comparison chart that managerial personnel and front-line staff are basically identical for the indicators of function of the 
safety sign as a reminder, the number of their choice of option A (safety signs play a great role) and the option B(safety signs play some role as a reminder) is almost same, which indicates that safety signs at workplace is noticed ,translated by personals and do play a role of guiding and alerting employees , meaning that safety sign system is really useful.

From the hazard- perception indication-personal comparison chart ,we can draw a conclusion that managerial personnel and front-line employee have great differences in risk perception perception, personal linear trend is partial normal, option $\mathrm{A}$ (one can exactly perceive the security risk in the workplace and illegal behavior) is much higher than option $\mathrm{B}$ (one can generally understand) and option $\mathrm{C}$ (one can't perceive), The investigation, interview shows that the experience of front-liner employees working in the machine workshop is almost more than 2 years and half of them is more than 10 years, therefore, they have their own perception and understanding for the equipment, operation flow, dangerous and harmful factors. While the phenomenon that the number of option B selected in the management is high is very normal. Because the management concerns the whole workshop from an overall perspective and have a weaker risk perception than front-line employees, the attention and support of safety for managements should be strengthened.

From the safety-knowledge indication-personal comparison chart, it informs that management and front-line staff's view is essentially identical for the issue that whether the safety signs increase the safety knowledge. The conclusion that the number of option A selected (safety signs effectively increase the safety knowledge ) is much higher than option B(safety signs increase some safety knowledge ) and C(safety signs don't increase the safety knowledge ) demonstrates that safety signs system in the workplace is useful and do play a supposed role ,and it extend the safety knowledge of employees and make them adhere to instructions of the safety signs in the daily work voluntarily .

From the safety-awareness indication-personal comparison chart, it informs that management and front-line staff's view is essentially the same for the issue that whether the safety signs increase the safety awareness. The number of option A selected (safety signs have a good effect on strengthening safety awareness) is almost equal and it is much higher than the number of option $\mathrm{B}$ (safety signs have some effect) and option C( safety signs have no effect ), which manifests that safety signs effectively increase the safety awareness of machining workshop staff, making them take safety seriously in their mind and follow the instructions of safety signs .

From the safety-habit indication-personal Comparison chart ,we can find that management and front-line staff's view is basically the same for the issue that safety signs increase the safety habit, namely, the safety signs system in workplace is effective, and management develop a good safety command habit and operations develop a safety operation habit which indicates safety signs system does have an effect on reminding and instructing staff's behaviors and it improves safety signs system can help to develop safety habit of staff, indicates that safety signs actually take function in safety note, instructions, guiding behaviors of employees, and improve the safety knowledge, safety awareness and safety habit, and it also improves the habitual behavior of employees, which can greatly reduce disposable unsafe behaviors, to avoid accidents and loss.

\section{CONCLUSION}

Above all, the paper obtains some conclusions as following:

(1)The vast majority (more than60\%) employees think safety signs workplace useful. And managers force on whether safety signs reasonable and appropriate, and whether safety signs can control safety behaviors; while employee force whether safety signs relate to their facilities and equipment and process.

(2)Both managers and front-line employees pay attention to safety signs in the workplace, nearly $80 \%$, which means staff follow with interest in safety signs.

(3)The managers and front-line employees hold the same view on the function of safety signs. Over $70 \%$ of managers and front-line employees think that safety signs can prompt danger.

(4)Managers and front-line employees have great difference in hazard perception, and the front-line employees care more about the function that safety signs can improve their hazard perception.

(5)Over $65 \%$ of the managers and front-line employees think that safety signs in the workplace can increase their safety knowledge, meaning safety signs in the workplace are useful, and they do take effect and increase safety knowledge of staff.

(6)Over $75 \%$ of the managers and front-line employees think that safety signs improve their safety awareness. It shows that safety signs improve the safety awareness of employees in the machining welding workshop, making staff value safe in their thoughts, and operate in accordance with safety signs consciously and follow the instructions of safety signs voluntary.

(7)Over $80 \%$ of the managers and front-line employees think that safety signs system can help to develop safety habit of staff, indicates that safety signs actually take function in safety note, instructions, guiding behaviors of employees, and improve the safety knowledge, safety awareness and safety habit, and it also improves the habitual behavior of employees, which can greatly reduce disposable unsafe behaviors, to avoid accidents and loss.

\section{ACKNOWLEDGEMENT}

The Fundamental Research Funds for the Central Universities(the project number:2013QZ02 ).

\section{REFERENCES}

[1] J.P.Yuan. An empirical study on the factors affecting the effectiveness of safety signs[D]. Zhejiang University,2009. 
[2] Alan H S Chan, Annie W Y Ng. Effects of sign characteristics and training methods on safety sign training effectiveness[J]. Ergonomics, 2010, 53(11):1325-1346.

[3] J.Bian. Study on the perception mechanism of safety signs and design factors in safety management--based on neural Industrial Engineering Perspective[D].

[4] Zhejiang University,2014 Paton, Nic. Senior. Managers Fail to Show Competence in Health and Safety[J]. Occupational Health, 2008, 60( 3): 6.

[5] Gwang-Hee Kim, Seok-Hoon Nam, S.J.Hwang, Hee-Bok Choi. Evaluation Construction Workers' Understanding of Safety Signs[J]. Applied Mechanics and Materials, 2013:291-294.

[6] Herber, John W..Quality problems as process safety warning signs[J]. Process Safety Progress, 2013(32), 2:175-178. 